\title{
Susceptibility to Multiple Sclerosis Associated with an Immunoglobulin Gamma 3 Restriction Fragment Length Polymorphism
}

\author{
Candy Newby Gaiser, M. Jacqueline Johnson, Gerda de Lange, \\ Laura Rassenti, Luigi L. Cavalli-Sforza, and Lawrence Steinman \\ Departments of Neurology and Genetics, Stanford University School of Medicine, Stanford, California 94305; \\ *Centraal Laboratorium van de Bloed Transfusiedienst van het Nederlandse, Rode Kruis Amsterdam, Netherlands
}

\begin{abstract}
Susceptibility to multiple sclerosis (MS) has been linked to the immunoglobulin $\mathbf{G}(\mathrm{Gm})$ markers as well as HLA-DR genes. We have used a genomic Ig gamma 1 probe which detects polymorphisms in the gamma 1, gamma 2, gamma 3 and pseudogamma genes to identify restriction fragment length polymorphisms associated with MS. A negative association was found between a 5.9-kilobase (kb) Bst EII gamma 3 fragment and MS. Southern blot analysis of genomic DNA revealed the presence of this fragment in 84 of 140 (60.0\%) controls, but in only 17 of 59 (28.8\%) MS patients. The frequency of the fragment in 47 myasthenia gravis and 16 Graves' disease patients was similar to that in controls, 60.0 and $62.5 \%$, respectively.
\end{abstract}

\section{Introduction}

Multiple sclerosis (MS) ${ }^{1}$ is a multifactorial disease in which genetic and environmental factors have a major influence on disease susceptibility. The cause and pathogenesis of MS are unclear. Immune abnormalities involving infection, autoimmunity, or a combination of both have been postulated (1). The nature of these environmental factors, however, remains an enigma. Early viral infection (childhood or adolescent) has long been suspected, based on several "MS epidemics" (2-6). To date, no virus has been definitively implicated nor has a target antigen, subject to autoimmune attack comparable to the acetylcholine receptor in myasthenia gravis (7), been identified in MS. Genes from two major complexes, the HLA-DR region of the human major histocompatibility complex (MHC) and the immunoglobulin structural gene region, have been shown to control immune responses to a wide variety of antigens (8-13) and in many cases to be associated with susceptibility to a number of diseases with

Address reprint requests to Dr. Steinman, Department of Neurology, C338, Stanford University Medical Center, Stanford, CA 94305. Dr. Johnson's present address is Hybritech, 11095 Torreyana Rd., San Diego, CA 92121 . Dr. de Lange's current address is Department of Immunogenetics, Central Laboratory of the Netherlands Red Cross Blood Transfusion Service, Amsterdam, The Netherlands.

Received for publication 29 July 1986.

1. Abbreviations used in this paper: CSF, cerebrospinal fluid; MG, myasthenia gravis; MHC, major histocompatibility complex; MS, multiple sclerosis; RFLP, restriction fragment length polymorphisms.

J. Clin. Invest.

(C) The American Society for Clinical Investigation, Inc.

0021-9738/87/01/0309/05 $\$ 1.00$

Volume 79, January 1987, 309-313 a demonstrated or suspected autoimmune component (14-27). The association of HLA-DR with MS has been widely reported (28-30), while the association of immunoglobulin allotype with MS has been reported only twice $(19,31)$. Using conventional Gm serotyping, Pandey et al. (19) compared the frequencies of the five phenotypes generated from the three common Caucasian Gm haplotypes and found the Gm1,17;21(za:g) phenotype to be increased in frequency in $70 \mathrm{MS}$ patients (relative risk of 3.6). At the same time, Propert et al. (31) reported elevated frequencies of $\mathrm{Gm}(\mathrm{a})$ and $\mathrm{Gm}(\mathrm{ax})$ among 40 MS patients.

Recently, Johnson et al. (32) and Migone et al. (33) have described DNA restriction fragment length polymorphisms (RFLPs) marking the gamma 1, gamma 2, gamma 3, pseudogamma, alpha, epsilon, and mu switch region immunoglobulin heavy chain genes. With these markers, the number of haplotypes has been expanded to more than $\mathbf{4 0}$ in the Caucasian population. The increase in detectable $\mathrm{Gm}$ variation should allow finer dissection of disease associations with this important immunogenetic region. We report here the first association between MS and a DNA level restriction fragment length polymorphism that maps to the immunoglobulin gamma 3 locus.

\section{Methods}

Sample collection. 59 unrelated Caucasian patients with MS were randomly selected from the neurology clinics at Stanford University and from neurology services in Paris and Rennes, France. All patients had definite MS diagnosed by a neurologist using inclusion criteria defined by Werner and Ellison (34). Patients with myasthenia gravis were drawn from clinics either at Stanford (25 patients) or the University of Dusseldorf (22 patients). The 16 patients with Graves' disease were obtained from the Stanford clinics. Control samples were taken from 140 normal Caucasian individuals from northern California.

DNA extraction and hybridization. DNA was extracted from peripheral leukocytes (35), digested with the appropriate restriction enzyme (Bethesda Research Laboratory, Gaithersburg, MD), and electrophoresed in $0.8 \%$ agarose horizontal gels for either 18 or $38 \mathrm{~h}$. DNA was transferred (36) onto nitrocellulose (Schleicher and Schuell, Keene, NH) or Zetabind (AMF) filters in 20X SSPE ( $1 \mathrm{X}=0.18 \mathrm{M} \mathrm{NaCl}, 10 \mathrm{mM} \mathrm{NaH2PO4,} 1$ $\mathrm{mM} \mathrm{Na}{ }_{2}$ EDTA, pH 7.0). DNA probes were either nick translated (37) or oligolabeled (38) to a specific activity of $>1 \times 10^{8} \mathrm{cpm} / \mu \mathrm{g}$. The Ig gamma 1 probe is carried as a 7.2-kb insert in a pBR322 recombinant plasmid and was kindly provided by Dr. Tasuku Honjo (Osaka University, Osaka, Japan). Filters were hybridized for $48 \mathrm{~h}$ at $42^{\circ} \mathrm{C}$ with $3 \times 10^{6}$ $\mathrm{cpm} / \mathrm{ml}$ in hybridization solution consisting of $50 \%$ formamide, $1 \mathrm{X}$ Denhardt's solution, $0.1 \%$ sodium dodecyl sulfate (SDS) and $100 \mu \mathrm{g} / \mathrm{ml}$ salmon sperm DNA. Washes to remove nonspecifically bound probe were done in $0.1 \mathrm{X}$ SSPE, $0.1 \%$ SDS for $1 \mathrm{~h}$ at $65^{\circ} \mathrm{C}$ and the filters were exposed with film (Kodak XAR-5, Eastman Kodak Co., Rochester, NY) between two lightning plus intensifying screens (E. I. DuPont de Nemours, Wilmington, DE). Films were developed after $3 \mathrm{~d}$, and again after $1-2$ wk. 
Protein typing. Plasma samples were typed for the following markers: G1m (z, a, x, f); G2m (n), G3m (g, b0, b1, b3, b5, s, t, c3, c5), A2m (1, 2) and $\mathrm{Km}(1,3)$, located on gamma 1, gamma 2, gamma 3 , alpha 2 , and kappa chains. Typing was carried out with the conventional hemagglutination inhibition technique in microtiter plates with reagents described previously (39).

\section{Results}

RFLPs marking the gamma 1, gamma 2, gamma 3, and pseudo gamma immunoglobulin heavy chain loci detected using an Ig gamma 1 probe have been described by Johnson et al. (32). 59 Caucasian MS patients (33 from the Stanford area and 26 from Paris, France), 47 myasthenia gravis (MG) patients, 16 Graves' disease patients, and 140 normal control individuals were typed for these markers. The most striking difference between MS patients and controls was found in the frequency of a 5.9-kb Bst EII gamma 3 restriction fragment (Fig. 1). Among controls, 84 of $140(60.0 \%)$ individuals possessed the $5.9-\mathrm{kb}$ fragment, while only 17 of the $59(28.8 \%)$ MS patients had this restriction fragment (Table I). This difference is significant at $P<0.001$ for the two groups taken together and at $P<0.01$ and $P<0.001$ for the Stanford and the French groups compared separately with the controls; the two MS groups, however, do not differ significantly from each other. The frequency of the fragment in 47 myasthenia gravis and 16 Graves' disease patients was comparable to that in controls (60.0 and $62.5 \%$, respectively).

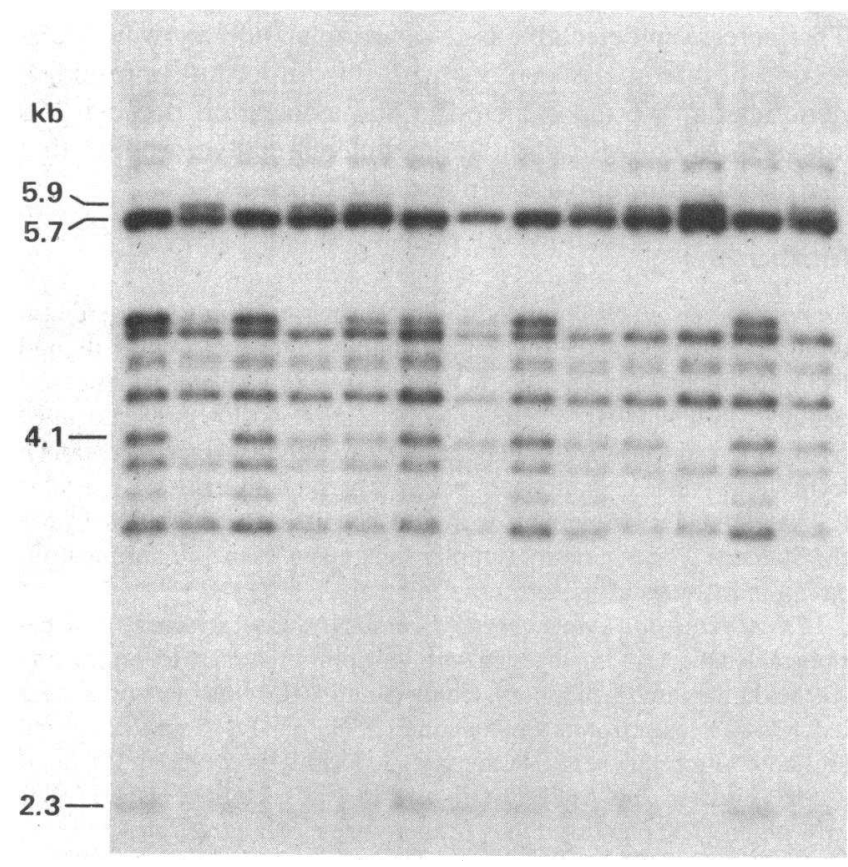

Figure 1. Autoradiogram after hybridization to the Ig gamma 1 probe of Bst EII digested DNA from MS patients (lanes 6-10) and normal controls (1-5, 11-13) illustrating the gamma 3 genotypes: $5.9 / 5.9 \mathrm{~kb}$ homozygotes, lanes 2,$11 ; 5.9 / 4.1-2.3 \mathrm{~kb}$ heterozygotes, lanes $5,9,10$, $13 ; 5.9 / 4.1-2.2 \mathrm{~kb}$ heterozygotes, lane $4 ; 4.1-2.3 / 4.1-2.2 \mathrm{~kb}$ heterozygotes, lanes 3, 8; and 4.1-2.3/4.1-2.3 kb homozygotes, lanes 1, 6, 7, 12. The molecular weights $(\mathrm{kb})$ of the analyzed DNA fragments are indicated. The DNA samples were gel electrophoresed for two days to allow adequate separation of the 5.9- and 5.7-kb bands, hence the 2.2$\mathrm{kb}$ fragments were not retained on this gel. Parallel 1-d gels were run to score fragments of $<2.3 \mathrm{~kb}$.
Table I. Presence of 5.9-kb Bst EII Restriction Fragment after Hybridization to Ig Gamma 1 Probe

\begin{tabular}{lll}
\hline & $\begin{array}{l}\text { Number of individuals } \\
\text { positive for } 5.9 \mathrm{~kb} \\
\text { fragment/Total number } \\
\text { tested (percent) }\end{array}$ \\
\hline Multiple sclerosis patients & & \\
Stanford & $11 / 33$ & $(33.3)$ \\
French & $6 / 26$ & $(23.1)$ \\
Combined & $17 / 59$ & $(28.8)$ \\
Myasthenia gravis patients & & \\
Stanford & $16 / 25$ & $(64.0)$ \\
German & $12 / 22$ & $(54.5)$ \\
Combined & $28 / 47$ & $(60.0)$ \\
Graves' disease patients & $10 / 16$ & $(62.5)$ \\
Normal controls & $84 / 140$ & $(60.0)$ \\
\end{tabular}

$\chi^{2}=7.67, \mathrm{df}=1, P<0.01$ for Stanford MS patients vs. controls. $\chi^{2}=12.04, \mathrm{df}=1, P<0.001$ for French MS patients vs. control. $\chi^{2}=15.14, \mathrm{df}=1, P<0.001$ for combined MS patients vs. controls.

There are two alternative alleles to the 5.9-kb fragment, the more frequent a combination of two fragments of 4.1 and 2.3 $\mathrm{kb}$, and an uncommon allele marked by fragments of 4.1 and $2.2 \mathrm{~kb}$. The three alleles are inherited codominantly in a Mendelian fashion and their relative frequencies in the general population (Caucasian) are 0.380 (5.9 kb), $0.583(4.1-2.3 \mathrm{~kb})$, and $0.037(4.1-2.2 \mathrm{~kb})(32)$. The latter two were pooled in Table II as the $4.1-2.2-\mathrm{kb}$ allele is about equally rare in all the populations (controls and the three patient groups). The frequencies of the various genotypes are significantly different between MS patients and controls $\left(\chi^{2}=13.78, \mathrm{df}=4, P<0.01\right)$, and one can easily see that the significance is entirely in the comparison of MS patients to controls $\left(\chi^{2}=12.68, \mathrm{df}=2, P<0.01\right)$. The MG patients are similar to controls $\left(\chi^{2}=0.06, \mathrm{df}=2, P>0.50\right)$.

All three populations of Table II taken separately are in Hardy Weinberg equilibrium:

Control:

$$
\chi^{2}=1.89, \quad \text { df }=1, \quad P>0.10
$$

Multiple sclerosis: $\quad \chi^{2}=1.01, \quad \mathrm{df}=1, \quad P>0.30$

Myasthenia gravis: $\chi^{2}=0.56, \quad$ df $=1, \quad P>0.50$

Table II. Distribution of Bst EII Gamma 3 Genotypes in MS and MG Patients and in Normal Controls ( $n=$ Number of Individuals)

\begin{tabular}{llll}
\hline Gamma 3 Bst EII & MS patients & MG patients & Normal controls \\
\hline & $\%$ & $\%$ & $\%$
\end{tabular}

\section{Genotype}

$\begin{array}{cccc}5.9 / 5.9 \text { aa } & 3 & 6 & 22 \\ & (5.1) & (17.8) & (16.4) \\ 5.9 / 4.1 \mathrm{Aa} & 15 & 14 & 55 \\ & (25.4) & (41.1) & (41.0) \\ 4.1 / 4.1 \mathrm{AA} & 41 & 14 & 57 \\ & (69.5) & (41.1) & (42.5)\end{array}$

Total $(n)$

59

34

134

$\chi^{2}=13.78, \mathrm{df}=4, P<0.01$.

$\chi^{2}=12.68, \mathrm{df}=2, P<0.01$ for MS patients vs. controls.

$\chi^{2}=0.06, \mathrm{df}=2, P>0.95$ for MG patients vs. controls. 
with the frequencies of the 5.9-kb allele of 0.1780 in MS patients, 0.3824 in MG patients, and 0.3694 in controls. A direct comparison of the gamma 3 allele frequencies for MS patients and controls (Table III) yields̀ a highly significant $\chi^{2}$ value of 14.01 (df $=1, P<0.001$ ).

A simple interpretation is that the risk of disease varies in the three genotypes AA:Aa:aa as $\mathrm{m}^{2}: \mathrm{m}: 1$ where A represents the 4.1-kb allele which is associated with increased disease susceptibility and a, the alternative $5.9 \mathrm{~kb}$ allele. It is well known (40) that when fitness coefficients (risk coefficient in this case) are in a geometric progression, $\mathrm{m}^{2}: \mathrm{m}: 1$, then the selected population is in Hardy Weinberg proportions with gene frequencies A: pm/ $(p m+q)$ and $a: q /(p m+q)$ where $p$ and $q$ are the gene frequencies of $A$ and $a$ in the control population and $m$ the risk coefficient in the heterozygote. One can show that the two quantities, $p$ and $m$, can be obtained by maximum likelihood by calculating $p$ in the usual way from the control population only, and $\mathrm{m}$ as the risk ratio of the gene frequencies (Table III) $\mathrm{m}=(99 \times 97) /$ $(21 \times 169)=2.706$. This risk ratio tends to be smaller, and hence cannot be directly compared with values obtained by the usual method in which two selected phenotypes are contrasted among controls and affected, without distinguishing homozygotes from heterozygotes (the relative risk calculated in the latter manner is 3.5). If the assumption of a geometric progression of risk in the three genotypes, and hence that Hardy Weinberg proportions hold in both controls and diseased, as here, then calculating risks taking account of gene dose in the way suggested here seems preferable.

80 individuals (27 MS, $18 \mathrm{MG}$, and 35 controls) were typed for the classical serologically defined Gm markers including $\mathrm{z}$, a, $x, f$ for gamma 1, and $\mathrm{g}, \mathrm{b0}, \mathrm{b1}, \mathrm{b3}$, b5 for gamma 3, as well as the Bst EII gamma 3 RFLP markers. As Table IV illustrates, there is a highly nonrandom association between the serologically defined and RFLP defined gamma 3 markers $\left(\chi^{2}=146.04\right.$, df $=4, P \ll 0.001)$. G3m g is strongly associated with the $5.9-\mathrm{kb}$ Bst EII fragment, while G3m b (b= b0, b1, b3, b5 in Caucasians) is highly associated with the 4.1-kb Bst EII fragment. Both alleles, 4.1-2.3 and 4.1-2.2 $\mathrm{kb}$, are associated with the G3mb allotype which occurs as a "long" complex of all four G3mb subspecificities in all of the MS, MG, and Graves' disease patients as well as all the (Caucasian) controls.

\section{Discussion}

We found the strongest association with MS to be with the Ig gamma 3 genes rather than the Ig gamma 1 genes as might have been expected on the basis of clinical observations (41-45). Sev-

Table III. Allele Frequencies for the Gamma 3 Bst EII Alleles in MS Patients and Normal Controls ( $n=$ Number of Alleles)

\begin{tabular}{lll}
\hline Bst Ell Gamma 3 allele & MS patients & Normal controls \\
\hline & $\%$ & $\%$ \\
$4.1 \mathrm{~kb} \mathrm{~A}$ & 21 & 99 \\
& $(0.1780)$ & $(0.3694)$ \\
$5.9 \mathrm{~kb} \mathrm{a}$ & 97 & 169 \\
& $(0.8220)$ & $(0.6306)$ \\
Total & 118 & 268 \\
\hline
\end{tabular}

$\chi^{2}=14.01, \mathrm{df}=1, P<0.001$.
Table IV. Nonrandom Association Between the Bst EII

Gamma 3 Alleles and the Classical Gm

Gamma 3 Alleles ( $n=$ Number of Individuals)

\begin{tabular}{llllc}
\hline \multicolumn{5}{c}{ Bst EII Gamma 3 Genotype } \\
\hline & & $5.9 / 5.9$ & $5.9 / 4.1$ & $4.1 / 4.1$ \\
G3m Genotype & $\mathrm{b} / \mathrm{b}^{*}$ & 0 & 2 & 41 \\
& $\mathrm{~b} / \mathrm{g}$ & 0 & 25 & 1 \\
& $\mathrm{~g} / \mathrm{g}$ & 11 & 0 & 0 \\
\hline
\end{tabular}

$\chi^{2}=146.04, \mathrm{df}=4, P \ll 0.001$.

* All individuals typing as $\mathrm{G} 3 \mathrm{~m}$ b were positive for all $\mathrm{G} 3 \mathrm{~m}$ b specificities: b0, b1, b3, and b5.

eral investigators report IgG1 to be the predominant subclass of IgG in cerebrospinal fluid (CSF) of MS patients $(43,44)$. Vartdal and Vandvik (45) report that of 19 MS patients with intrathecally synthesized bands of oligoclonal IgG in the CSF, the oligoclonal IgG in 15 was restricted to the IgG1 subclass. IgG3 bands were found in only four patients and in each case IgG1 bands were observed along with the IgG3 bands. 14 of the 15 MS patients displayed intrathecal synthesis of oligoclonal varicella zoster and measles virus specific IgG1 antibodies. No viral specific antibodies of any other IgG subclass were found in serum or CSF of these patients. Salier et al. (41) found a preferential synthesis of $\mathrm{G} 1 \mathrm{~m} 1$ (a) antibodies among MS patients heterozygous for G1m 1 and G1m 3. Strong linkage disequilibrium between the G1m and G3m alleles may explain this gamma 1 allele preference; however, we did not find a significant association between a gamma I MbO I RFLP (32) and MS (data not shown) despite the highly significant gamma 3 RFLP association.

Linkage between immunoglobulin $\mathrm{Gm}$ allotypes and MS has been reported previously $(19,31)$. This is the first demonstration of a DNA level RFLP (mapping to the Ig gamma 3 locus) associated with this disease. Moreover, this association, significant at the genotypic level at $P<0.01$ is even stronger at the level of the allele, with the gene frequencies of the 4.1 and 5.9-kb alleles differing between MS patients and controls at $P$ $<0.001$. It is interesting to note, that while our results show a comparable relative risk value (3.5) to that reported in the other studies of Pandey et al. (19) and Propert et al. (31), susceptibility is associated with the opposite allotype, $\mathrm{Gm}$ fb (that is, the 4.1$\mathrm{kb}$ Bst EII allele). This risk was calculated by phenotype without taking gene dose into account. Recently, Haile et al. (46) have also noted an excess of $\mathrm{Gm}$ fb individuals in a study of MS patients from multiplex families.

Geographical stratification and local variation in ethnic composition may account in part for the differences in these studies. Indeed, comparisons of the $\mathrm{Gm}$ phenotypic distributions of the control groups reveal variation bordering on significance. In studies of the relationship of MS to HLA markers there is considerable geographic variation. In northern Europe, North America, and Australia there is an association between MS (Caucasians) and HLA DR2 DW2 (47). This association does not hold in northern Italy (48), Jordan (49), or Israel (50) in Caucasian MS patients. In Italy and Jordan, MS is associated with DRw4.

It is also possible that different environmental "triggering" factors selecting different (susceptible genotypes may be involved. For example, if infection with any of several viruses can potentially initiate MS pathogenesis in susceptible individuals, then 
it is likely that a variety of immunogenetic backgrounds, that is, different allelic combinations at the HLA-DR and/or immunoglobulin loci, may prove differentially susceptible/resistant depending on the particular virus encountered. However, it is noteworthy that both the Stanford and French MS groups in our study show the same significant elevation of the $4.1-\mathrm{kb}$ gamma 3 allele frequency. The results from the various studies suggest the possibility of significant genetic influences overlaid against a complex and heterogeneous background of environmental factors. The study of MS isolates may be critical to the unraveling of this interplay in MS etiology.

\section{Acknowledgments}

We thank Dr. Daniel Cohen, Dr. E. Schuller, and Dr. O. Sabouraud for kindly providing DNA samples from the French MS patients, Dr. Klaus Toyka for providing samples from the German myasthenia gravis patients, and Dr. Joseph Kriss for providing samples from the Stanford Graves' disease patients. We also thank Berta Young, Peter van Eede, and Fred van Leeuwen for expert technical assistance.

This research was supported by the National Multiple Sclerosis Society and by National Institutes of Health grant GM 28428 .

\section{References}

1. Paterson, P. Y. 1978. The demyelinating diseases: clinical and experimental studies in animals and man. Immunological Diseases. 2: 1400-1435.

2. Kurtzke, J. F., and K. Hyllested. 1979. Multiple sclerosis in the Faroe Islands: I. Clinical and epidemiological features. Ann. Neurol. 5: 6-21.

3. Kurtzke, J. F., K. R. Gudmundsson, and S. Bergmann. 1980. Multiple sclerosis in Iceland: a postwar epidemic. Neurology. (NY) 30: 437. (Abstr.)

4. Sheremata, W. A., D. C. Poskanzer, D. G. Withum, C. L. MacLeod, and M. E. Whiteside. 1985. Unusual occurrence on a tropical island of multiple sclerosis. Lancet. ii:618.

5. Visscher, B. R., C. B. Sullivan, R. Detels, D. L. Madden, J. L. Sever, P. I. Terasaki, M. S. Park, and J. P. Dudley. 1981. Measles antibody titers in multiple sclerosis patients and HLA-matched and unmatched siblings. Neurology. 31:1142-1145.

6. Koprowski, H., E. C. De Freitas, M. E. Harper, M. SandbergWollheim, W. A. Sheremata, M. Robert-Guroff, C. W. Saxinger, M. B. Feinberg, F. Wong-Staal, and R. C. Gallo. 1985. Multiple sclerosis and human T-cell lymphotropic retroviruses. Nature (Lond.). 318:154-160.

7. Lindstrom, J. M., B. L. Einarson, V. A. Lennon, and M. E. Seybold. 1976. Pathological methods in experimental myasthenia gravis. J. Expl. Med. 144:726-738.

8. Pandey, J. P., H. H. Fudenberg, G. Virella, C. U. Kyoung, C. B. Loadholt, R. M. Galbraith, E. C. Gotschlich, and J. C. Park. 1979. Association between immunoglobulin allotypes and immune response to Haemophilus influenzae and meningococcus polysaccharides. Lancet. i: 190-192.

9. Pandey, J. P., W. P. Zollinger, H. H. Fudenberg, and C. B. Loadholt. 1981. Immunoglobulin allotypes and immune response to meningococcal group B polysaccharide. J. Clin. Invest. 68:1378-1380.

10. Whittingham, S., J. D. Mathews, M. S. Schanfield, J. V. Mathews, D. B. Tait, P. J. Morris, and I. R. Mackay. 1980. Interactive effect of Gm allotypes and HLA-B locus antigens on the human antibody response to a bacterial antigen. Clin. Exp. Immunol. 40:8-15.

11. Schanfield, M. S., J. V. Wells, and H. H. Fudenberg. 1979. Immunoglobulin allotypes and response to tetanus toxoid in Papua, New Guinea. J. Immunogenet. 6:311-315.

12. Wells, J. V., H. H. Fudenberg, and I. R. Mackay. 1971. Relation of the human antibody response to flagella to $\mathrm{Gm}$ phenotype. J. Immunol. 107:1505-1511.
13. Nakao, Y., H. Matsumoto, T. Miyazaki, N. Mizuno, N. Arima, A. Wakisaka, K. A. Okimoto, Y. Kazawa, K. Tsuji, and T. Fujita. 1981. IgG heavy chain $(\mathrm{Gm})$ allotypes and immune response to insulin in insulin-requiring diabetics. $N$. Engl. J. Med. 304:407-410.

14. Nakao, Y., H. Matsumoto, T. Miyazaki, H. Nishitani, K. Ota, T. Fujita, and K. Tsuji. 1980. Gm allotypes in myasthenia gravis. Lancet. i:677-680.

15. Farid, N. R., R. M. Newton, E. P. Noel, and W. H. Marshall. 1977. Gm phenotypes in autoimmune thyroid disease. J. Immunogenet. 4:429-434.

16. Schultheis, E., H. H. Reter, and H. Deichen. 1975. GM(1) and $\mathrm{Gm}(2)$ immunoglobulin allotypes in patients with malignant melanoma. Humangenetik. 28:177-181.

17. Nakao, Y., H. Matsumoto, T. Miyazaki, H. Nishitani, K. Takatsuki, R. Kasukawa, S. Nakayama, S. Izumi, T. Fujita, and K. Tsuji. 1980. IgG heavy chain allotypes (Gm) in autoimmune diseases. Clin. Exp. Immunol. 42:20-26.

18. Whittingham, S., J. D. Mathew, M. S. Schanfield, B. D. Tait, and I. R. Mackay. 1981. Interaction of HLA and Gm in autoimmune chronic active hepatitis. Clin. Exp. Immunol. 43:80-86.

19. Pandey, J. P., J. M. Goust; J. P. Salier, and H. H. Fudenberg. 1981. Immunoglobulin $G$ heavy chain $(\mathrm{Gm})$ allotypes in multiple sclerosis. J. Clin. Invest. 67:1797-1800.

20. Uno, H., T. Sasazuki, H. Tamai, and H. Matsumoto: 1981. Two major genes, linked to HLA and Gm, control susceptibility to Graves' disease. Nature (Lond.). 292:768-770.

21. Morell, A., H. Kaser, R. Scherz, and F. Skvaril. 1977. Evidence for an association between uncommon $\mathrm{Gm}$ phenotypes and neuroblastoma. Lancet. i:23-24.

22. Weitkamp, L. R., L. Nee, B. Keats, R. J. Polinsky, and S. Guttormsen. 1983. Alzheimer disease: evidence for susceptibility loci on chromosomes 6 and 14. Am. J. Hum. Genet. 35:443-453.

23. Kagnoff, M. F., J. B. Weiss, R. J. Brown, T. Lee, and M. S Schanfield. 1983. Immunoglobulin allotype markers and HLA A, HLA $B$, and HLA DR locus antigens in gluten-sensitive enteropathy. Lancet. i:952-953.

24. Pollack, M. S., B. Safai, P. L. Myskowski, J. M. Gold, J. Pandey, and B. Dupont. 1983. Frequencies of HLA and Gm immunogenetic markers in Kaposi's sarcoma. Tissue Antigens. 21:1-8.

25. Ockhuizen, T., J. P. Pandey, R. W. Veltri, H. Arlen, and H. H. Fudenberg. 1982. Immunoglobulin allotypes in patients with squamous cell carcinoma of the head and neck. Cancer. 49:2021-2024.

26. Sanders, P. A., G. G. de Lange, P. A. Dyer, and D. M. Grennan. 1985. Gm and $\mathrm{Km}$ allotypes in rheumatoid arthritis. Ann. Rheum. Dis. 44:529-532.

27. Willcox, N., A. A. G. Demaine, J. Newsom-Davis, K. I. Welsh, S. A. Robb, and S. G. Spiro. 1985. Increased frequency of IgG heavy chain marker $\mathrm{G} 1 \mathrm{~m}(2)$ and HLA-B8 in Lambert-Eaton myasthenic syndrome with and without associated lung carcinoma. Hum. Immunol. 14:29-36.

28. Spielman, R. S., and N. Nathanson. 1982. The genetics of susceptibility to multiple sclerosis. Epidemiol. Rev. 4:45-73.

29. Ryder, L. P., and A. Svejgaard. 1981. Genetics of HLA disease association. Annu. Rev. Genet. 15:169-187.

30. Svejgaard, A., P. Platz, and P. Ryder. 1983. HLA and disease 1982-a survey. Immunol. Rev. 70:193-218.

31. Propert, D. N., C. C. A. Bernard, and M. J. Simons, M. J. 1982 $\mathrm{Gm}$ allotypes and multiple sclerosis. J. Immunogenet. 9:359-361.

32. Johnson, M. J., G. G. de Lange, and L. L. Cavalli-Sforza. 1986 Ig gamma restriction fragment length polymorphisms indicate an ancient separation of Caucasian haplotypes. Am. J. Hum. Genet. 38:617-640.

33. Migone, N., J. Feder, H. Cann, B. van West, J. Hwang, N. Takahashi, T. Honjo, A. Piazza, and L. L. Cavalli-Sforza. 1983. Multiple DNA fragment polymorphisms associated with immunoglobulin mu chain switch-like regions in man. Proc. Natl. Acad. Sci. USA. 80:467471.

34. Weiner, H. L., and G. W. Ellison. 1983. A working protocol to be used as a guideline for trials in MS. Arch. Neurol. 40:704-706. 
35. Feder, J., L. Yen, E. Wijsman, L. Wang, L. Wilkins, J. Schroder, N. Spurr, H. Cann, M. Blumenberg, and L. L. Cavalli-Sforza. 1985. A systematic approach for detecting high frequency restriction fragment length polymorphisms using large genomic probes. Am. J. Hum. Genet. 37:635-649.

36. Southern, E. M. 1975. Detection of specific sequences among DNA separated by gel electrophoresis. J. Mol. Biol. 98:503-517.

37. Rigby, P., M. Dieckmann, C. Rhodes, and P. Berg. 1977. Labelling deoxyribonucleic acid to high specific activity in vitro by nick translation with DNA polymerase I. J. Mol. Biol. 113:237-251.

38. Feinberg, A. P., and B. Vogelstein. 1983. A technique for radiolabelling DNA restriction endonuclease fragments to high specific activity. Anal. Biochem. 132(1):6-13.

39. de Lange, G., P. Wright, P. van Eede, F. van Leeuwen, H. T. Long, and N. T. O. Hong. 1984. Association between leprosy and immunoglobulin allotypes: $\mathrm{Gm}-\mathrm{A} 2 \mathrm{~m}$ and $\mathrm{Km}$ frequencies in Vietnamese. J. Immunogenet. 11:173-180.

40. Li, C. C. 1976. First Course in Population Genetics. The Boxwood Press, Pacific Grove, CA. 410-412.

41. Salier, J. P., J. M. Goust, J. P. Pandey, and H. H. Fudenberg. 1981. Preferential synthesis of the $\mathrm{Gl}$ (1) allotype of $\mathrm{IgG} 1$ in the central nervous system of multiple sclerosis patients. Science (Wash. DC). 213 $1400-1402$.

42. Salier, J. P., P. Glynn, J. M. Goust, and H. L. Cuzner. 1983. Distribution of nominal and latent IgG $(\mathrm{Gm})$ allotypes in plaques of multiple sclerosis brain. Clin. Exp. Immunol. 54:634-640.
43. Palmer, D. L., B. J. Minard, and L. P. Cawley. 1976. IgG subgroups in cerebrospinal fluid in multiple sclerosis (letter). $N$. Engl. J. Med. 294:446-448.

44. Vandvik, B., J. B. Natvig, and D. Wiger. 1976. IgG1 subclass restriction of oligoclonal IgG from cerebrospinal fluids and brain extracts in patients with multiple sclerosis and subacute encephalitides. Scand. J. Immunol. 5:427-436.

45. Vartdal, F., and B. Vandvik, B. 1983. Multiple sclerosis: subclasses of intrathecally synthesized IgG and measles and varicella zoster virus IgG antibodies. Clin. Exp. Immunol. 54:641-647.

46. Haile, R. W. C., A. Goldstein, L. Field, and M. L. Marazita. 1985. A linkage analysis of the $\mathrm{Gm}$ locus and multiple sclerosis. Genet. Epidemiol. 2:29-34.

47. Batchelor, J. R., A. Compston, and W. I. McDonald. 1978. The significance of the association between HLA and MS. Br. Med. Bull. 34: 279-284.

48. Zibetti, A., C. L. Cozullo, E. Smeraldi, and R. Scorza-Smeraldi. 1977. HLA typing on Italtian multiple sclerosis population. Boll. Ist. Sieroter Milan. 56:539-543.

49. Kurdi, A., I. Ayesh, and A. Alodallat et al. 1977. Different B lymphocyte alloantigens associated with MS in Arabs and Northern Europeans. Lancet. i:1123-1125.

50. Brautbar, C., M. Alter, and E. Kahana. 1976. HLA antigens in MS. Neurology. 26:50-53. 